\title{
Veleszületett szívhibák sebészi kezelése 60 éves kor felett
}

\author{
Hartyánszky István dr. ${ }^{1}$ - Varga Sándor dr. ${ }^{1}$ \\ Csepregi László dr. ${ }^{1}$ - Babik Barna dr. ${ }^{2}$ - Simon Judit ${ }^{2}$ \\ Havasi Kálmán ${ }^{3}$ - Kalapos Anita ${ }^{3}$ - Bogáts Gábor dr. ${ }^{1}$
}

\author{
Szegedi Tudományegyetem, Általános Orvostudományi Kar, Szent-Györgyi Albert Klinikai Központ, \\ ${ }^{1}$ Szívsebészeti Osztály, ${ }^{2}$ Aneszteziológiai és Intenzív Terápiás Osztály, ${ }^{3}$ II. Belgyógyászati Klinika, Szeged
}

\begin{abstract}
Bevezetés: A szívhibákkal született betegek száma és életkora növekszik. Célkitüzés: A szerzők arra a kérdésre kerestek választ, milyen számban és eredménnyel operálhatók az idős, 60 év felettiek veleszületett szívhibái. Módszer: 20132015 között 77 felnőtt, 36 negyvenévesnél fiatalabb és 41 idősebb, köztük 12 hatvanéves kor feletti beteget operáltak. A különböző mútétek száma a következő volt (zárójelben az egyes korcsoportokban végzett mútétek száma): $5(3,2,0)$ Ross, $19(12,1,6)$ aortamúbillentyú-beültetés, $1(0,0,1)$ subaorticus membránreszekció, $8(4,3,1)$ Bentall/aorta ascendens cseréje, $5(0,3,2)$ myectomia mitralismúbillentyú-beültetéssel vagy a nélkül, $1(1,0,0)$ coarctatio aortae rekonstrukciója, $2(1,1,0)$ ductus arteriosus ligatura, $4(0,3,1)$ jobbkamra-kifolyási pálya rekonstrukciója biológiai múbillentyúvel, $5(5,0,0)$ homograft, $1(0,1,0)$ BioValsalva-beültetés, $3(1,2,0)$ teljes atrioventricularis septumdefektus primer rekonstrukciója, $2(1,1,0)$ múbillentyú-beültetés, $10(4,6,0)$ kamrai septumdefektus, $5(2,3,0)$ pitvari septumdefektus zárása, $1(1,0,0)$ teljes cavopulmonalis anasztomózis, $1(0,1,0)$ congenitalis korrigált nagyér-transzpozíció múbillentyü-beültetéssel, $2(0,1,1)$ Ebstein-betegségben billentyüplasztika és $2(1,0$, 1) múbillentyú-beültetés. Eredmények: Mütéti mortalitás nem volt, korai halálozás l esetben teljes cavopulmonalis anasztomózis mútét után fordult elő többszervi elégtelenség miatt. Következtetések: Számolni kell az egyre magasabb életkorú veleszületett szívhibás betegekkel, akiknél a szívbetegség jó eredménnyel korrigálható 60 éves életkor felett is a congenitalis és szerzett szívhibák megoldásában jártas szívsebészeti osztályon. Orv. Hetil., 2016, 157(21), 820824.
\end{abstract}

Kulcsszavak: veleszületett szívhibák sebészete időskorban

\section{Surgical management of congenital heart defects beyond the age of 60}

Introduction: The population with congenital heart disease is increasing and ageing. Aim: The aim of the authors was to examine the outcome of surgical management of congenital heart diseases beyond the age of 60 years. Method: Between 2013 and 2015, 77 adults were operated (36 younger, and 41 older than forty years, including 12 patients aged over 60 years. The numbers of procedures were as follows (in brackets the number of operations in the three age groups): Ross surgery $5(3,2,0)$; aortic valve replacement $19(12,1,6)$; subaortic membrane resection $1(0,0$, $1)$; Bentall/ascending aortic plasty $8(4,3,1)$; myectomy with or without mitral valve replacement in left ventricular outflow obstruction $5(0,3,2)$; aortic coarctation $1(1,0,0)$; ligation of ductus arteriosus $2(1,1,0)$; reconstruction of right ventricular outflow tract with biological valve $4(0,3,1)$; homograft $5(5,0,0)$; BioValsalva graft $1(0,1,0)$; primary reconstruction of complete atrioventricular septum defect $3(1,2,0)$; valve replacement $2(1,1,0)$; ventricular septum defect $10(4,6,0)$; atrial septum defect closure $5(2,3,0)$; total cavopulmonal anastomosis $1(1,0$, $0)$; valve replacement in congenital transposition of great arteries $1(0,1,0)$, Ebstein operation with valve plasty 2 $(0,1,1)$; valve replacement $2(1,0,1)$. Results: There was no operative mortality, while early mortality occurred in one patient with total cavopulmonal anastomosis due to multiorgan failure. Conclusions: Congenital heart defects can be operated beyond the age of 60 years with good results in a tertiary heart centre having great experience in the management of congenital and acquired heart disease.

Keywords: congenital heart disease, surgical management in elderly age

Hartyánszky, I. Varga, S., Csepregi, L., Babik, B., Simon, J., Havasi, K., Kalapos, A., Bogáts, G. [Surgical management of congenital heart defects beyond the age of 60]. Orv. Hetil., 2016, 157(21), 820-824.

(Beérkezett: 2016. február 6.; elfogadva: 2016. március 16.) 


\section{Rövidítések}

ASD = pitvari septumdefektus; AV valve = atrioventricularis billentyü; BT-sönt = Blalock-Taussig-sönt; CAVSD = komplett atrioventricularis septumdefektus; cTGA $=$ congenitalis korrigált nagyér-transzpozíció; LVOTO = balkamra-kiáramlási pálya szúkülete; MAPCAs = arteria pulmonalis collateralisok; $\mathrm{PA}=$ pulmonalis atresia; $\mathrm{PS}=$ pulmonalis stenosis; $\mathrm{RDA}=$ jobb deszcendáló coronariaarteria; RVOT = jobbkamra-kiáramlási pálya; TCPC $=$ teljes cavopulmonalis anasztomózis; TGA = nagyér-transzpozíció; UVSZ = univentricularis szív

A szívhibával született betegek egyre nagyobb számban élik meg a késői felnőttkort, és növekszik a száma azoknak, akik az idősebb, a 60 év feletti életkort. Az életkor előrehaladtával újabb és újabb megoldandó problémák jelentkeznek, amelyek kihívást jelentenek a kardiológusok, szívsebészek számára [1-4]. Kérdés, hogy szabad-e ebben az életkorban operálni ezeket a betegeket; milyen az eredmény, mekkora a kockázat? Az időskorban észlelt, gondozott veleszületett szívbetegségek morbiditásáról, mortalitásáról már készülttek vizsgálatok, felmérések [57], de e betegcsoport sebészi kezelésének eredményéről még nem számoltak be. Vizsgálatunk célja, hogy felmérjük, a késői felnőttkorban, idősebb korban, különösen 60 éves kor felett milyen eredménnyel operálhatók a különböző veleszületett szívhibák.

\section{Módszer}

A Szegedi Tudományegyetem, Szent-Györgyi Albert Klinikai Központ Szívsebészeti Osztályán 2013-2015 között 77 felnőttkorú (16-75 év) veleszületett szívhibás betegen végeztek szívmútétet: 36 fiatal (40 évesnél fiatalabb) felnőtttkorú, 41 (40 évesnél idősebb) idősebb felnőttkorú betegen, akik közül tizenkettő 60 évesnél idősebb volt. A mútéti típusok megoszlását az 1 . táblázat tartalmazza.

Legnagyobb számban, 24-en, congenitalis aortabillentyü-stenosis miatt kerültek mútétre. Ismerten gyermekkoruktól ellenőrzés alatt álltak, kettőnél megelőzően valvulotomia, múbillentyü-beültetés is történt csecsemő-, illetve gyermekkorban. Öt esetben Ross-mútétet, 19 esetben múbillentyú-beültetést végeztek. Súlyos szűkületet okozó subaorticus membrán észlelése 72 éves korban történt, a membrán kimetszését a billentyú cseréjével egészítették ki. Fallot-IV, Marfan-szindróma esetében kialakult aortagyök/ascendens tágulat, aneurysma kialakulása miatt Bentall-mútétre, aortagyök-plasztikára, illetve aortaascendens-cserére 8 esetben került sor. Aortaisthmus-szúkület fokozódó súlyosbodása felnőttkorra indikált mútétet, a két ductus arteriosus persistens intervenciós zárása sikertelen volt, illetve arra nem volt alkalmas. A balkamra-kifolyási pálya hypertrophiás szúkületét myectomiával \pm mitralis billentyú eltávolításával és mübillentyú-beültetéssel 5 esetben lehetett megoldani.
A jobbkamra-kifolyási pálya szúkületét (Fallot-IV, PA + VSD rekonstrukció, PS + intakt kamrai septum + ASD-zárás után, Ross-mútét miatt) 4 biológiai billentyú, 5 homograft, I BioValsalva beültetéssel/cserével korrigálták. A hemodinamikailag határesetet képező (részben residualis) VSD-k és az ASD zárásakor az infektív endocarditis és a stroke megelőzése is szempont volt. A komplett AV septumdefektus 3 esetben (kettónél M. Down társult) primer rekonstrukcióra került, 2 megelőzően rekonstruált esetben mitralis múbillentyú beültetése történt meg. Többszöri palliációs (BT-sönt, bidirekcionális Glenn-mútét) beavatkozások után TCPC-komplettálás történt egy UVSZ-betegen. Izolált congenitalisan korrigált nagyér-transzpozíciós betegen a szisztémás kamra AV-billentyújének cseréje történt múbillentyưre. Ebstein-betegség miatt két esetben a tricuspidalis billentyú plasztikája, 2 esetben az előzőleg plasztikázott billentyúk múbillentyúre történő cseréje vált szükségessé (1. táblázat).

\section{Eredmények}

Mútéti mortalitás nem volt. A TCPC-vel operált fiatal felnőttet vesztették el a korai posztoperatív szakban sokszervi, dominálóan májelégtelenség miatt. A NYHA IIIIV. stádiumban levő betegek I-II. stádiumba kerültek.

\section{Megbeszélés}

A felnőttkort elért veleszületett szívhibás betegeknél eltérő problémák jelentkeznek fiatal, illetve idős életkorban. A fiatalság felső határát 40 éves korban állapítják meg. A fiatalkorúaknál a munkavállalás, sportolás, családalapítás, terhesség vállalás/kihordás, szülés, betegség öröklődésének kérdése jelenti a problémát. Időskorban a hangsúly arra tevődik át, hogy az időskori betegségek (diabetes, hypertonia, arteriosclerosis) milyen mértékben befolyásolják az alapbetegséget, hogyan járulnak hozzá az esetleges keringési elégtelenség kialakulásához, különösen akkor, ha residualis kamradiszfunkciók, söntök, billentyúbetegségek, ritmuszavarok vannak jelen [5-7].

E korcsoportban a cerebrovascularis betegségek sokkal magasabb százalékban fordulnak elő, mint a normálpopulációban [8], a cyanosis miatti magas hiperviszkozitás vagy a nagy számban jelentkező pitvarfibrilláció, a residualis söntökön keresztüli paradox embolisatio miatt [8]. Cyanoticus betegekben a stroke elófordulása 4-14\% $[9,10]$. A stroke a vezetó halálok coarctatio aortaes betegekben is, de a magas számban társuló intracranialis aneurysma is jelentôsen növeli e betegeknél a neurológiai szövődményeket $[11,12]$. Cerebrovascularis történések magas számban fordulnak még elő ASD, Senningmútött nagyér-transzpozíciós betegeknél „residualis baffle leak" esetén, Fontan-keringésben és mechanikus múbillentyú beültetése után [8]. A thromboemboliás 
1. táblázat $\mid$ Mútéti megoszlás az egyes korcsoportokban

ASD = pitvari septumdefektus; $\mathrm{AV}=$ atrioventricularis; $\mathrm{cTGA}=$ korrigált nagyér-transzpozíció; MAPCAs = arteria pulmonalis collateralisok; PS = pulmonalis stenosis $;$ TCPC $=$ teljes cavopulmonalis anasztomózis; UVSZ = univentricularis szív; VSD = kamrai septumdefektus

\begin{tabular}{|c|c|c|c|}
\hline & 16-40 év & 40-60 év & $60-75$ év \\
\hline Ross-mütét & 3 & 2 & \\
\hline Aortamübillentyü-beültetés & 12 & 1 & 7 \\
\hline Aorta vitium izoláltan & 5 & 1 & 1 \\
\hline St. p. op. ductus arteriosus & 1 & & \\
\hline St. p. op. Ross, endocarditis & 1 & & \\
\hline St. p. op. coarctatio aortae & 1 & & 1 \\
\hline $\begin{array}{l}\text { St. p. op. aortamúbillentyú- } \\
\text { beültetés }\end{array}$ & 1 & & \\
\hline + VSD-zárás & 1 & & \\
\hline Marfan-szindróma & 2 & & 1 \\
\hline St. p. op. ASD-zárás & & & 1 \\
\hline + ASD-zárás & & & 1 \\
\hline + Subaorticus membrán reszekciója & & & 1 \\
\hline Situs inversus totalis & & & 1 \\
\hline $\begin{array}{l}\text { Bentall-mütét, aortagyök-plasztika, } \\
\text { aorta ascendens cseréje }\end{array}$ & 4 & 3 & 1 \\
\hline + VSD-zárás & 1 & & \\
\hline cTGA, VSD, PS, endocarditis & 1 & & \\
\hline $\begin{array}{l}+ \text { Homograftcsere } \\
\text { (st. p. op. PA + VSD + MAPCAs) }\end{array}$ & 1 & & \\
\hline Marfan-szindróma & 1 & 1 & \\
\hline St. p. op. Fallot-IV & & 1 & \\
\hline St. p. múbillentyú-beültetés & & 1 & \\
\hline St. p. coarctatio aortae & & & 1 \\
\hline
\end{tabular}

szövődmények a Fontan típusú betegek vezető betegsége.

Congenitalis szívhibák és azok korrigálása után: bicuspidalis aortabillentyü, coarctatio aortae, nagyér-transzpozíció - arterialis switch mütét, hypoplasiás bal szívfél -, Norwood-mütét, Ross-mütét esetén magas számban jelentkezik mellkasi és hasi aortaaneurysma [13]. A felnőttkort megért korrigált Fallot-tetralógiás betegek harmadának dilatál az aortagyöke, ascendense [14]. Coarctatio aortae esetén jelentősen nő a rizikó aortaaneurysma és dissectio kialakulására [15].

A congenitalis coronariaanomáliákhoz társuló artheroscleroticus plakkok miatt sürübben jelentkezik hirtelen halál időskorban [16-18]. Coronariatranszfer-mütétek: TGA-switch, Ross-mútét után jelentősen emelkedik a coronaria orifitium stenosisa [19-23], de ebben az esetben korrekt adatok még nincsenek, mert e populáció még nem érte el az időskort.

Az időskorú betegeknél megnövekszik rizikófaktorként az extracardialis komorbiditás [24]. Májelégtelenség kialakulása jól dokumentált jobbszívfél-elégtelenség

\begin{tabular}{|c|c|c|c|}
\hline & 16-40 év & 40-60 év & $60-75$ év \\
\hline $\begin{array}{l}\text { Balkamra-kiáramlási pálya } \\
\text { obstrukciója }\end{array}$ & & 4 & 1 \\
\hline Myectomia & & 1 & \\
\hline + Mitralisbillentyú-csere & & 3 & 1 \\
\hline $\begin{array}{l}\text { Jobbkamra-kifolyási pályába } \\
\text { biológiai mübillentyü beültetése }\end{array}$ & & 3 & 1 \\
\hline St. p. op. pulmonalis stenosis & & 1 & \\
\hline St. p. op. Fallot-IV & & 2 & \\
\hline St. p. op. Fallot-trilógia & & & 1 \\
\hline Homograftcsere homograftra & 5 & & \\
\hline St. p. op. Ross-mútét & 2 & & \\
\hline St. p. op. Fallot-IV & 3 & & \\
\hline $\begin{array}{l}\text { Mübillentyücsere } \\
\text { BioValsalvára }\end{array}$ & & 1 & \\
\hline St. p. op. Fallot-IV & & 1 & \\
\hline $\begin{array}{l}\text { Komplett AV septumdefektus primer } \\
\text { rekonstrukcioja }\end{array}$ & 1 & 2 & \\
\hline$A V$-billentyü-csere & 1 & 1 & \\
\hline Kamrai septumdefektus zárása & 4 & 6 & \\
\hline Pitvari septumdefektus zárása & 2 & 3 & \\
\hline Coarctatio aortae korrekciója & 1 & & \\
\hline $\begin{array}{l}\text { Ebstein-betegség Tricuspidalis } \\
\text { billentyü plasztikája }\end{array}$ & & 1 & 1 \\
\hline Tricuspidalis billentyü cseréje & 1 & & 1 \\
\hline UVSZ-TCPC & 1 & & \\
\hline Ductus arteriosus zárása & 1 & 1 & \\
\hline cTGA AV billentyü cseréje & & 1 & \\
\hline Összesen & 36 & 29 & 12 \\
\hline
\end{tabular}

esetén [25]. Fontan-betegeknél a magas centrális vénás nyomás, „low cardiac outpout”, megelőző többszöri mútéti beavatkozás miatt májelégtelenség, cirrhosis fejlődik ki [24-26]. A betegek 9\%-ában, különösen cyanoticus, Eisenmenger-szindrómás betegeknél, veseelégtelenség alakul ki [27]. E betegeknél nagyszámú a tüdő restruktív megbetegedése is $[24,28]$.

A fenti megállapításokat támasztja alá a tizenkét, 60 évesnél idősebb betegen történt beavatkozás szükségessége is:

1. 69 éves férfi betegbe (12 éves korában Fallot-trilógia miatt ASD-zárás, pulmonalis valvulotomia) extrém jobbszívfél-elégtelenség (NYHA IV. stádium) miatt biológiai múbillentyú beültetése pulmonalis pozícióba.

2. 72 éves nőbetegnél (8 éves korában ASD-zárás) a subaorticus membrán okozta súlyos szúkület, aortabillentyü-regurgitatio miatt membránreszekció és aorta biológiai múbillentyú beültetése.

3. 6l éves férfi betegnél coarctatio aortae miatt megelőzőleg mútét két ízben, most aortaaneurysma 
miatt mechanikus múbillentyű beültetése és aortaascendens-rekonstrukció, pótlás conduittal.

4. 70 éves nőbetegnél Ebstein-anomália (NYHA IIIII. stádium) miatt tricuspidalis billentyü plasztikája és ASD-zárás.

5. 71 éves nőbetegnél Ebstein-betegség miatt megelőző (5 év) tricuspidalis billentyü plasztikája után (NYHA III. stádium) most múbillentyü-beültetés.

6. 68 éves férfi betegnél (NYHA II-III. stádium) balkamra-kiáramlási pálya szúkülete miatt myectomia és mitralismúbillentyü-beültetés.

7. 65 éves nőbetegben (NYHA II-III. stádium) VSDzárás folttal, tricuspidalis billentyú plasztikája.

8. 62 éves férfi betegbe (megelőzőleg, 56 éves korában, coarctatio aortae miatt aortastent-, majd RDA coronariastent-beültetés) aortastenosis miatt biológiai aorta-múbillentyü beültetése.

9. 65 éves nőbetegbe (megelőzőleg 20 éve phlebothrombosis, pulmonalis embolia) mechanikus aortamúbillentyú beültetése és ASD-zárás.

10. 61 éves situs inversus totalisos férfi betegbe aorta biológiai múbillentyü beültetése.

11. 65 éves férfi betegbe aorta biológiai múbillentyü beültetése és tricuspidalis billentyü plasztikája.

12. 75 éves férfi betegbe (gyermekkora óta ismert bicuspidalis billentyü, aortastenosis) biológiai múbillentyü beültetése történt.

A vizsgálatok idáig arra terjedtek ki, hogy a veleszületett szívhibás betegek morbiditása és mortalitása - elérve az idős-, gerontológiai kort, különösen 60 év felett - hogyan viszonyul a normálpopulációhoz [5-7]. Arról adat, hogy e betegségeknek sebészi korrigálása ebben az életkorban elvégezhetö-e és milyen eredménnyel, még nem áll rendelkezésünkre. Eredményeink szerint, megfelelő tapasztalattal rendelkező centrumokban jól korrigálhatók a veleszületett szívbetegségek időskorú betegeken is, és a korhatár kitolható 75 éves korig vagy tovább is.

Anyagi támogatás: A közlemény megírása, illetve a kapcsolódó kutatómunka anyagi támogatásban nem részesült.

Szerzői munkamegosztás: H. I., B. G.: A hipotézisek kidolgozása. H. I., B. G., Cs. L., H. K., K. A., B. B., S. J.: A vizsgálat lefolytatása. V. S., H. I.: Statisztikai elemzések. H. I., B. G.: A kézirat megszövegezése. A cikk végleges változatát valamennyi szerző elolvasta és jóváhagyta.

Érdekeltségek: A szerzőknek nincsenek érdekeltségeik.

\section{Irodalom}

[1] Hartyánszky, I., Varga, S., Havasi, K., et al.: Perspectives in the management of congenital heart defects in adult patients. [Perspektívák a veleszületett szívhibák felnőttkori sebészi kezelésében.] Orv. Hetil., 2015, 156(3), 92-97. [Hungarian]
[2] Havasi, K., Kalapos, A., Berek, K., et al.: More than 50 years' experience in the treatment of patients with congenital heart disease in a Hungarian university hospital. The basics of the CSONGRAD Registry. [Több mint 50 év tapasztalat a congenitalis szívbetegek ellátásában egy magyar egyetemi központban. A CSONGRÁD Regiszter alapadatai.] Orv. Hetil., 2015, 156(20), 794-800. [Hungarian]

[3] Congenital heart defects in adults. Cardiology guidelines. [Felnőttkori congenitalis szívhibák. A Kardiológiai Szakmai Kollégium útmutatója.] Medition Kiadó, Budapest, 2010. [Hungarian]

[4] Baumgartner, H., Bonhoeffer, P., De Groot, N. M., et al.: ESC guidelines for the management of grown-up congenital heart disease (new version 2010). Eur. Heart J., 2010, 31(23), 29152957.

[5] Tutarel, O., Kempny, A., Alonso-Gonzalez, R., et al.: Congenital heart disease beyond the age of 60: emergence of a new population with high resource utilization, high morbidity, and high mortality. Eur. Heart J., 2014, 35(11), 725-732.

[6] Afilalo, J., Therrien, J., Pilote, L., et al.: Geriatric congenital heart disease: burden of disease and predictors of mortality. J. Am. Coll. Cardiol., 2011, 58(14), 1509-1515.

[7] Lui, G. K., Fernandes, S., McElbinney, D. B.: Management of cardiovascular risk factors in adults with congenital heart disease. J. Am. Heart Assoc., 2014, 3(6), e001076.

[8] Hoffmann, A., Chockalingam, P., Balint, O. H., et al.: Cerebrovascular accidents in adult patients with congenital heart disease. Heart, 2010, 96(15), 1223-1226.

[9] Engelfriet, P., Boersma, E., Oechslin, E., et al.: The spectrum of adult congenital heart disease in Europe: morbidity and mortality in a 5 year follow-up period. The Euro Heart Survey on adult congenital heart disease. Eur. Heart J., 2005, 26(21), 23252333.

[10] Daliento, L., Somerville, J., Presbitero, P., et al.: Eisenmenger syndrome. Factors relating to deterioration and death. Eur. Heart J., 1998, 19(12), 1845-1855.

[11] Connolly, H. M., Huston, J. 3rd, Brown, R. D. Jr., et al.: Intracranial aneurysms in patients with coarctation of the aorta: a prospective magnetic resonance angiographic study of 100 patients. Mayo Clin. Proc., 2003, 78(12), 1491-1499.

[12] Cook, S. C., Hickey, J., Maul, T. M., et al.: Assessment of the cerebral circulation in adults with coarctation of the aorta. Congenit. Heart Dis., 2013, 8(4), 289-295.

[13] Verma, S., Siu, S. C.: Aortic dilatation in patients with bicuspid aortic valve. N. Engl. J. Med., 2014, 370(20), 1920-1929.

[14] Mongeon, F. P., Gurvitz, M. Z., Broberg, C. S., et al.: Aortic root dilatation in adults with surgically repaired tetralogy of Fallot: a multicenter cross sectional study. Circulation, 2013, 127(2), 172-179

[15] Horlick, E. M., McLaughlin, P. R., Benson, L. N.: The adult with repaired coarctation of the aorta. Curr. Cardiol. Rep., 2007, 9(4), 323-330.

[16] Lubiszewska, B., Gosiewska, E., Hoffman, P., et al.: Myocardial perfusion and function of the systemic right ventricle in patients after atrial switch procedure for complete transposition: longterm follow-up. J. Am. Coll. Cardiol., 2000, 36(4), 1365-1370.

[17] Millane, T., Bernard, E. J., Jaeggi, E., et al.: Role of ischemia and infarction in late right ventricular dysfunction after atrial repair of transposition of the great arteries. J. Am. Coll. Cardiol., 2000, 35(6), 1661-1668

[18] Singh, T. P., Humes, R. A., Muzik, O., et al.: Myocardial flow reserve in patients with a systemic right ventricle after atrial switch repair. J. Am. Coll. Cardiol., 2001, 37(8), 2120-2125.

[19] Raisky, O., Bergoend, E., Agnoletti, G., et al.: Late coronary artery lesions after neonatal arterial switch operation: results of surgical coronary revascularisation. Eur. J. Cardiothorac. Surg., 2007, 31(5), 894-898

[20] Ou, P., Khraiche, D., Celermajer, D. S., et al.: Mechanisms of coronary complications after the arterial switch for transposition 
of the great arteries. J. Thorac. Cardiovasc. Surg., 2013, 145(5),1263-1269.

[21] Raju, V., Burkbart, H. M., Durbam, L. A. 3rd, et al.: Reoperation after arterial switch: a 27-year experience. Ann. Thorac. Surg., 2013, 95(6), 2105-2112.

[22] Jussli-Melchers, J., Haneya, A., Hoffmann, G., et al.: Minimally invasive direct coronary artery bypass in a child with an occlusion of left main coronary artery after arterial switch operation. Interact. Cardiovasc. Thorac. Surg., 2013, 17(6), 1040-1041.

[23] Saini, A. P., Wolfe, L. T., Millington, K. A., et al.: Occult coronary ostial obstruction late after arterial switch operation. J. Card. Surg., 2013, 28(3), 308-311.

[24] Cohen, S. B., Ginde, S., Bartz, P. J., et al.: Extracardiac complications in adults with congenital heart disease. Congenit. Heart Dis., 2013, 8(5), 370-380.

[25] Naschitz, J. E., Slobodin, G., Lewis, R. J., et al.: Heart diseases af fecting the liver and liver diseases affecting the heart. Am. Heart J., 2000, 140(1), 111-120.
[26] Assenza, G. E., Graham, D. A., Landzberg, M. J., et al.: MELD XI score and cardiac mortality or transplantation in patients after Fontan surgery. Heart, 2013, 99(7), 491-496.

[27] Dimopoulos, K., Diller, G. P., Koltsida, E., et al.: MA. Prevalence, predictors, and prognostic value of renal dysfunction in adults with congenital heart disease. Circulation, 2008, 117(18), 2320-2328.

[28] Ginde, S., Bartz, P. J., Hill, G. D., et al.: Restrictive lung disease is an independent predictor of exercise intolerance in the adult with congenital heart disease. Congenit. Heart Dis., 2013, 8(3), 246-254.

\section{FELHÍVÁs folyóirat-referátumok beküldésére}

A Semmelweis Egyetem Továbbképző Központjának döntése értelmében 2016. január 1-jétől folyamatosan orvos-továbbképzési pontokat kaphatnak a nemzetközi, impaktfaktoros folyóiratokban megjelent közlemények rövid összefoglalásának, referátumának beküldöi.

Az Orvosi Hetilap hasábjain megjelenő és közlésre elfogadott referátum után 1 pont, félévente maximum 12 továbbképzési pont gyưjthető, amelyet félévente összesitve továbbitunk a továbbképzési központok felé.

Távoktatással szerzett pontokból évente legfeljebb 20 pont számitható be.

Aki továbbképzési pontot kiván gyüjteni, a referátum beküldésekor adja meg pecsétszámát.

Várjuk lelkes, továbbképzési pontokat gyüjteni kivánó referálóink jelentkezését!

\section{A referátum fejlécében az alábbi adatokat kérjük megadni:}

A cikk címe magyarul, zárójelben az angol cím

A szerző(k) neve (vezetéknév, a keresztnevet jelölö betü(k) - 3 szerzőig, háromnál több szerző esetén et al.), a levelező szerző neve, munkahelye és e-mail címe)

A folyóirat neve - a szokásos nemzetközi rövidítés szerint (PubMed), évszám, kötetszám, füzetszám, a cikk kezdő és utolsó oldalszáma

A referátumot elektronikus úton (Editorial Manager vagy e-mail: edit.budai@akademiai.hu) kérjük elküldeni. 